\title{
Silvia Disegni, Paul Alexis-Trublot: du vrai et du faux dans le naturalisme
}

Isabella Giovinazzo

\section{(2) OpenEdition}

\section{Edizione digitale}

URL: https://journals.openedition.org/studifrancesi/38157

DOI: 10.4000/studifrancesi.38157

ISSN: 2421-5856

\section{Editore}

Rosenberg \& Sellier

\section{Edizione cartacea}

Data di pubblicazione: 15 décembre 2004

Paginazione: 641

ISSN: 0039-2944

\section{Notizia bibliografica digitale}

Isabella Giovinazzo, «Silvia Disegni, Paul Alexis-Trublot: du vrai et du faux dans le naturalisme», Studi Francesi [Online], 144 (XLVIII | III) | 2004, online dal 30 novembre 2015, consultato il 08 mai 2021. URL: http://journals.openedition.org/studifrancesi/38157; DOI: https://doi.org/10.4000/studifrancesi. 38157

Questo documento è stato generato automaticamente il 8 mai 2021.

\section{(c)}

Studi Francesi è distribuita con Licenza Creative Commons Attribuzione - Non commerciale - Non opere derivate 4.0 Internazionale. 


\title{
Silvia Disegni, Paul Alexis-Trublot: $d u$ vrai et du faux dans le naturalisme
}

\author{
Isabella Giovinazzo
}

\section{NOTIZIA}

SILVIA DISEGNI, Paul Alexis-Trublot: du vrai et du faux dans le naturalisme, «Romantisme» n, 116 (II trim. 2002) pp. 85-96.

1 L'articolo definisce il contributo dato da Paul Alexis, amico e discepolo più fedele di Zola, alla diffusione e all'affermazione del naturalismo attraverso la sua attività editoriale, diramata in vari giornali dell'epoca. Paradossalmente, nelle sue cronache, le più famose delle quali sono firmate con lo pseudonimo di Trublot, l'autore utilizza modalità di scrittura che appartengono alla mistificazione letteraria, derivate dalla commistione tra tradizione romantica e romanzo "industriale", che confonde i piani di reale e fittizio, comico e tragico. In questo curioso atteggiamento è dunque possibile vedere una svalutazione della scrittura giornalistica, alla quale non è necessario applicare i canoni dell'estetica naturalista, ma anche una contestazione indiretta della stessa estetica, che in una certa misura avvicina Alexis alle più evidenti critiche riversate contro il naturalismo dai gruppi che annunciano la rivoluzione poetica attraverso i giornali della rive gauche. 